\title{
Characterization of cellulose structure of Populus plants modified in candidate cellulose
}

\section{biosynthesis genes}

Garima Bali $^{\mathrm{a}, \mathrm{b}}$, Ratayakorn Khunsupat ${ }^{\mathrm{a}}$, Hannah Akinosho ${ }^{\mathrm{a}, \mathrm{b}}$, Raja S Payyavula ${ }^{\mathrm{b}}$, Reichel Samuel ${ }^{\mathrm{a}}$, Gerald A. Tuskan ${ }^{\mathrm{b}}$, Udaya C. Kallurib§ ${ }^{\mathrm{b}}$, and Arthur J. Ragauskas ${ }^{\mathrm{a}, \mathrm{b}, \mathrm{c}^{*}}$

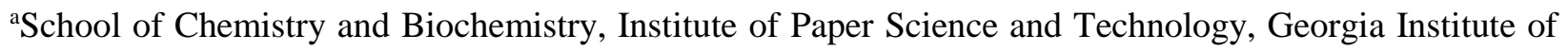
Technology, 500 10th St., Atlanta, GA, 30332

bioEnergy Science Center, Biosciences Division, Oak Ridge National Laboratory, Oak Ridge, TN, 37831

${ }^{\mathrm{c}}$ Department of Chemical and Biomolecular Engineering \& Department of Forestry, Wildlife, and Fisheries, University of Tennessee, Knoxville, TN 37996, USA.

This manuscript has been authored by UT-Battelle, LLC under contract no. DE-AC0500OR22725 with the U.S. Department of Energy. The publisher, by accepting the article for publication, acknowledges that the United States Government retains a non-exclusive, paid-up, irrevocable, world-wide license to publish or reproduce the published form of this manuscript, or allow others to do so, for United States Government purposes. The Department of Energy will provide public access to these results of federally sponsored research in accordance with the DOE Public Access Plan (http://energy.gov/downloads/doe-public-access-plan)

* Correspondence to: Arthur J. Ragauskas, Department of Chemical and Biomolecular Engineering \& Department of Forestry, Wildlife, and Fisheries, University of Tennessee, Knoxville, TN 37996, USA. E-mail: aragausk@utk.edu, Tel.: +1 865-974-2042; Fax: +1 865-974-7076

$\S$ Corresponding author at: Biosciences Division, Oak Ridge National Laboratory, P.O. Box 2008 MS6422, Oak Ridge, TN, 37831-6422 USA. Tel.: +1 865241 6895; Fax: +1 8655769939. 


\begin{abstract}
The recalcitrant nature of lignocellulosic biomass is a combined effect of several factors such as high crystallinity and high degree of polymerization of cellulose, lignin content and structure, and the available surface area for enzymatic degradation (i.e., accessibility). Genetic improvement of feedstock cell wall properties is a path to reducing recalcitrance of lignocellulosic biomass and improving conversion to various biofuels. An advanced understanding of the cellulose biosynthesis pathway is essential to precisely modify cellulose properties of plant cell walls. Here we report on the impact of modified expression of candidate cellulose biosynthesis pathway genes on the ultra-structure of cellulose, a key carbohydrate polymer of Populus cell wall using advanced nuclear magnetic resonance approaches. Noteworthy changes were observed in the cell wall characteristics of downregulated KORRIGAN 1 (KOR) and KOR 2 transgenic plants in comparison to the wild-type control. It was observed that all of the transgenic lines showed variation in cellulose ultrastructure, increase in cellulose crystallinity and decrease in the cellulose degree of polymerization. Additionally, the properties of cellulose allomorph abundance and accessibility were found to be variable. Application of such cellulose characterization techniques beyond the traditional measurement of cellulose abundance to comprehensive studies of cellulose properties in larger transgenic and naturally variable populations is expected to provide deeper insights into the complex nature of lignocellulosic material, which can significantly contribute to the development of precisely tailored plants for enhanced biofuels production.
\end{abstract}

Keywords: Cellulose biosynthesis. Gene. Crystallinity. Micro-fibril. Degree of polymerization 


\section{Introduction}

In recent years, biofuels have emerged as a clean, domestic and sustainable energy resource to meet growing demands and to displace fossil fuel consumption [1,2]. In addition to energy security, biofuels offer a large potential in mitigating issues related to climate change. Of the various competing biomass to biofuels technologies, the biochemical conversion of lignocellulosic biomass to biofuels is being widely developed. For second-generation biofuels, non-edible lignocellulosic materials are currently pursued as a favorable substrate for the production of biofuels and other specialty chemicals [3, $4]$.

Lignocellulosic biomass is primarily composed of cellulose, hemicellulose and lignin, which in combination comprise the complex plant cell wall [5]. Cellulose is a linear polymer of D-glucose units linked by $\beta$-1,4-glycosidic bonds, where the hydroxyl groups in each unit form intra- and inter-molecular hydrogen bonds that stiffen the chain and give it a rigid and partially crystalline structure. This crystallinity gives cellulose a more ordered structure that limits enzyme accessibility during saccharification[6, 7]. Hemicellulose, on the other hand, is a complex carbohydrate structure composed of various five and six carbon sugars such as xylose, arabinose, glucose, galactose and mannose. Hemicellulose essentially provides the entire cell wall with more rigidity by interacting with cellulose micro-fibrils and cross-linkages with lignin [8]. Lignin, the third primary component of the secondary plant cell wall, is a polyphenolic polymer attached to hemicelluloses [9] and is highly resistant to enzymatic degradation. Lignin hinders plant cell wall deconstruction by inhibiting the accessibility of $\beta$ glucosidases and other enzymes to cellulose [10]. Consequently, the bioconversion of complex carbohydrates derived from lignocellulosic biomass remains challenging. Recalcitrance then is the result of several factors including 1) high crystallinity and degree of polymerization (DP) for cellulose, 2) lignin content/structure and 3) the accessible surface area available to enzymatic hydrolysis [11].

Recalcitrance can drive the cost of the entire cellulosic biofuels conversion process higher and thus pose challenging commercialization issues. One of the promising options to tailor the properties of feedstocks is via genetic modification of plant cell wall chemistry and structure [12]. Genetically 
modified plant biomass is expected to require milder pretreatment conditions and lower enzyme dosages for the release of fermentable sugars. Such modifications are expected to substantially reduce the capital costs associated with the production of biofuels from lignocelluloses and thus pave a way for commercialization. Genetic manipulation of feedstocks, such as switchgrass [13], aspen [14], tobacco [15] and alfalfa [16], have been reported to significantly reduce recalcitrance. Several researchers have that shown manipulating cellulose biosynthesis in tobacco resulted in $30 \%$ enhancement in cellulose content and 20\% increase in overall biomass yield [17]. And, Guo et al. [16] reported a strong negative correlation between the lignin content and sugar release in transgenic alfalfa compared with wild-type controls. A recent study from Foston et al. reported a three-fold increase in the sugar release from Populus tension wood, which was in part due to the increase of cellulose accumulation in the G-layer [18]. Further aspects of cellulose biosynthesis have been discussed in detail in numerous previous publications $[19,20]$.

While it is recognized that an advanced understanding of the cellulose biosynthesis pathway is essential to precisely modify the properties of usable fraction of plant cell walls, the use of traditional cellulose characterization, generally restricted to quantitation of cellulose, merits the development and application of new characterization methods. Therefore, we focused on two KORRIGAN (KOR)-like candidate cellulose biosynthesis pathway genes, belonging to the endo-1,4-beta-D-glucanase gene family in order to evaluate the value of using advanced nuclear magnetic resonance (NMR) techniques. Cellulose substrate is from Uridine 5 '-diphosphate (UDP)-glucose, which is derived from sucrose after hydrolysis by either invertase or sucrose synthase following phosphorylation through UDP-glucose pyrophosphorylase [UGPase, 21]. Using the proposed sitosterol $\beta$-glycosides as a primer, Cellulose synthase (CesA) along with other interacting proteins such as endo-1,4- $\beta$-glucanases (EGase) form cellulose chains $[22,23]$.

KOR, a plasma-membrane-bound EGase has been found to be highly associated with cellulose synthesis and is required for normal cell wall assembly, cell elongation and proper xylem development 
[24], as well as maintenance of cellulose crystallinity [25]. Protein modeling suggests that KOR is an integral part of CesA complex; however, this has not been confirmed in the co-precipitation studies that alternatively suggest that KOR function in post deposition stages [24, 26]

Substantial advances have recently been made in our understanding of the cellulose biosynthesis pathway and our ability to obtain value-added cellulose from biomass for production of secondgeneration biofuel. Several properties of cellulose, such as crystallinity, allomorph distribution, microfibril size and degree of polymerization have previously been reported to influence the biomass saccharification efficiency [27]. A recent study by Payyavula et al. [28] indicated that cellulose biosynthesis Populus RNAi transgenic lines of KORRIGAN (PdKOR1, and PdKOR2) showed important changes in xylem cell wall formation resulting in significantly reduced plant height, supporting the functional roles for $P d K O R 1$, and $P d K O R 2$ in cell wall formation and for altering biomass composition and differential carbon allocation in an entire plant.

Using advanced NMR techniques, we investigated cellulose properties, such as cellulose quantity, crystallinity, degree of polymerization, allomorph abundance and accessibility, in the native and transgenic lines of model bioenergy plant Populus. The results presented here provide valuable insights for developing improved biomass species with improved cell wall traits, which in turn, can be leveraged for development of precisely tailored plants for enhanced biofuels production.

\section{Methods}

\subsection{Generation of transgenic plants}

Roughly 200 bp 3'UTR region specific to each isoform, PdKORI (Poptri.003G151700; primer F: CACCCCCGGGGCTGCAATAGAGTTTGGACTT,

R:TCTAGATACTAAGTATATCACAAAATCAGACAGA) and PdKOR2 (Poptri.001G078900, primer F: CACCCCCGGGGTAAAGATAATGCGACTCCA, R:

TCTAGACATATCATACACATATACTATTTATATCAA), was amplified from Populus deltoides (and 
RNAi construct was developed in the pAGSM552 binary vector. Plant transformation was performed at ArborGen LLC, Ridgeville, SC using the Agrobacterium method. More than 15 independent transgenic lines were analyzed in our preliminary study. Additional studies including the estimation of cellulose structural differences were performed on two selected transgenic lines for each isoform (PdKORI-1, PdKOR1-2, PdKOR2-1 and PdKOR2-2). Initially, plants were propagated in small tubes $(0.5 \mathrm{~L})$ until they reached $40-50 \mathrm{~cm}$, after which they were moved to bigger pots (6 L). Five ramets of each clonally replicated transgenic line and control (i.e., empty vector transformed plants) were grown in a greenhouse at $\mathrm{ORNL}$ maintained at $25^{\circ} \mathrm{C}, 16 \mathrm{~h}$ light for approximately 180 days. Actively growing stems of transgenic and control Populus lines were destructively sampled, air dried and stored until used for further cellulose characterization studies.

\subsection{Sample preparation for cellulose analysis}

Stems of transgenic and control Populus were ground in a Wiley mill to pass through an 840 micron sieve. The milled samples were stored at $20^{\circ} \mathrm{C}$ until needed. Samples were extracted with dichloromethane $(6 \mathrm{x}-70 \mathrm{~mL})$ in Foss Soxtec unit $\left(\operatorname{Soxtec}^{\mathrm{TM}} 2050\right)$ at $80^{\circ} \mathrm{C}$ following a 4 -step extraction procedure.

\subsection{Cellulose and hemicellulose isolation}

Delignification of Populus samples was performed using peracetic acid as reported earlier [29]. In brief, ground and extractive-free Populus samples $(0.6 \mathrm{~g})$ were mixed with peracetic acid $(2.1 \mathrm{~g})$ and deionized water $(4.8 \mathrm{~mL})$. This mixture was then stirred at $25^{\circ} \mathrm{C}$ for $24 \mathrm{~h}$ followed by repeated centrifugation and washing with deionized water to isolate the holocellulose samples. Cellulose was isolated from the holocellulose $(0.10 \mathrm{~g})$ by extraction with a $17.5 \% \mathrm{NaOH}$ solution $(5 \mathrm{~mL})$ at $25^{\circ} \mathrm{C}$ for 2 h. The mixture was diluted to $8.75 \% \mathrm{NaOH}$ solution by addition of $5 \mathrm{~mL}$ of deionized water and repeated stirring at $25^{\circ} \mathrm{C}$ for an additional $2 \mathrm{~h}$. The isolated $\alpha$-cellulose samples were then collected by centrifugation, washed with $50 \mathrm{~mL}$ of $1 \%$ acetic acid and an excess of deionized water and air-dried. For

hemicellulose isolation, the supernatant obtained above, was poured into a mixture of ethanol:acetic acid 
(70:30, v:v). The supernatant was removed by centrifugation and the precipitated hemicellulose was again washed with a mixture of ethanol: acetic acid (70:30, v: v) and air-dried for analysis.

\section{Sample preparation for solid-state nuclear magnetic resonance}

The cellulose samples for NMR were prepared from the transgenic and control Populus lines from the holocellulose sample $(1.0 \mathrm{~g})$ by hydrolysis for $4 \mathrm{~h}$ in $\mathrm{HCl}(100 \mathrm{~mL}$ of $2.5 \mathrm{M})$ under reflux. The isolated $\alpha$-cellulose samples were then collected by filtration rinsed with an excess of deionized water and dried in a fume hood.

\subsection{Solid-state NMR analysis}

For NMR analysis, 4-mm cylindrical ceramic MAS rotors were filled with the isolated $\alpha$ cellulose. Solid-state NMR measurements were carried out on a Bruker Avance-400 spectrometer operating at a frequency of $100.55 \mathrm{MHz}$ for ${ }^{13} \mathrm{C}$ in a Bruker double-resonance MAS probe at spinning speeds of $10 \mathrm{kHz}$. CP/MAS experiments utilizing a $5 \mathrm{~ms}\left(90^{\circ}\right)$ proton pulse, $1.5 \mathrm{~ms}$ contact pulse, $4 \mathrm{~s}$ recycle delay and 4-8 K scans. All spectra were recorded on equilibrated moisture samples ( 35\% water content). The line-fitting analysis of spectra was performed using NUTS NMR Data Processing software (Acorn NMR, Inc.).

\subsection{Gel Permeation Chromatography analysis of cellulose}

The weight-average molecular weights were determined by gel permeation chromatography (GPC) after tricarbanilation of cellulose [30]. Cellulose $(15 \mathrm{mg})$ from each sample was placed in separate test tubes equipped with micro stir bars and dried overnight under vacuum at $40^{\circ} \mathrm{C}$. Each test tube was capped with rubber septa, anhydrous pyridine $(4 \mathrm{~mL})$ and phenyl isocyanate $(0.5 \mathrm{~mL})$ were added sequentially via syringe and the test tubes were placed in an oil bath at $70^{\circ} \mathrm{C}$ and allowed to stir for $48 \mathrm{~h}$. Methanol $(1 \mathrm{~mL})$ was then added to quench the phenyl isocyanate. The contents of each test tube were then added dropwise to $7: 3(\mathrm{v}: \mathrm{v})$ methanol:water mixture $(100 \mathrm{~mL})$ to precipitate the derivatized cellulose. The solids were collected by filtration and then washed with the same methanol:water mixture $(1 \times 50 \mathrm{~mL})$ followed by deionized water $(2 \times 50 \mathrm{~mL})$. The derivatized cellulose was then dried overnight under vacuum at $40^{\circ} \mathrm{C}$. Prior to GPC analysis, the derivatized cellulose was dissolved in tetrahydrofuran 
(THF) $(1 \mathrm{mg} / \mathrm{mL})$, filtered through a $0.45 \mathrm{~mm}$ filter and placed in a $2-\mathrm{mL}$ auto-sampler vial. The molecular weight distributions of the cellulose tricarbanilate samples were analyzed on an Agilent GPC Security 1200 system equipped with four Waters Styragel columns (HR1, HR2, HR4, HR5), Agilent refractive index (RI) detector and Agilent UV detector $(270 \mathrm{~nm})$ using THF as the mobile phase (1 $\mathrm{mL} / \mathrm{min}$ ) with injection volumes of $0.02 \mathrm{ml}$. A calibration curve was constructed based on eight narrow polystyrene standards ranging in molecular weight from $1.5 \times 10^{3}$ to $3.6 \times 10^{6} \mathrm{~g} / \mathrm{mol}$. Data collection and processing were performed using Polymer Standards Service WinGPC Unity software (Build 6807). Molecular weights were calculated by the software relative to the universal polystyrene calibration curve and weight-average degree of polymerization $\left(\mathrm{DP}_{\mathrm{w}}\right)$ were obtained by dividing $\mathrm{M}_{\mathrm{w}}$ by $519 \mathrm{~g} / \mathrm{mol}$, the molecular weight of the tricarbanilated cellulose repeat unit.

\subsection{GPC analysis of hemicellulose}

The GPC analyses were carried out using an Agilent 1200 series HPLC system consisting of an on-line degasser and an auto-sampler, a RI detector and three columns of Ultrahydrogel 120, 250 and 500 (Waters Inc., USA) linked in series. The RI detector was set at $35^{\circ} \mathrm{C}$. The mobile phase was an alkaline sodium hydroxide/acetate solution ( $0.2 \mathrm{M}$ sodium hydroxide, $0.1 \mathrm{M}$ sodium acetate, $\mathrm{pH} 12-13)$ and the flow rate was $0.5 \mathrm{~mL} / \mathrm{min}$. The hemicellulose samples were dissolved in mobile phase $(\sim 1 \mathrm{mg} / \mathrm{mL})$ and the solution was then filtered with a $0.2 \mu \mathrm{m}$ filter. The filtered sample $(25 \mu \mathrm{L})$ was injected into the GPC column system for analysis. Pullulan standard samples were used for the calibration [31].

\subsection{Lignin characterization by heteronuclear single-quantum correlation ${ }^{1} \mathrm{H}-{ }^{13} \mathrm{C} N \mathrm{NR}$ analysis}

Prior to the NMR analysis, Populus samples were subjected to a cellulysin-cellulase treatment for the partial removal of polysaccharides using a modified procedure described earlier [32, 33]. The ligninrich sample was dissolved in anhydrous perdeuterated pyridinium chloride-DMSO- $\mathrm{d}_{6}(1: 4$, v:v) solvent system. The ${ }^{13} \mathrm{C}-{ }^{1} \mathrm{H} 2 \mathrm{D}$ heteronuclear single-quantum correlation (HSQC) NMR experiments were carried out at $55^{\circ} \mathrm{C}$ in a Bruker Avance $400 \mathrm{MHz}$ spectrometer equipped with a z-gradient triple-resonance probe. The HSQC analysis was performed using a standard Bruker pulse sequence with a $90^{\circ} \mathrm{C}$ pulse, $0.11 \mathrm{~s}$ acquisition time, a $0.5 \mathrm{~s}$ pulse delay, a ${ }^{1} \mathrm{~J} \mathrm{C}-\mathrm{H}$ of $145 \mathrm{~Hz}$ and acquisition of 256 data points. 


\subsection{Error analysis}

For cellulose and hemicellulose analysis, 3 ramets per transgenic line $(n=3)$ and 5 ramets for control $(n=5)$ were measured. The values for degree of polymerization (DP) and cellulose crystallinity (CrI) in transgenic and control lines were summarized as mean \pm standard error across the ramets. The errors associated with paracrystalline, $I_{\alpha}, I_{\beta}, I_{\alpha+\beta}$ and the amorphous domains in the line fitting were found to be $\pm 3.0, \pm 1.5, \pm 1.3, \pm 2.0$ and $\pm 3.1 \%$, respectively. Student $\mathrm{t}$-tests were performed to determine significance between experimental values, where $p \leq 0.05$ is $95 \%$ significance $(*)$ and $p \leq 0.01$ is $99 \%$ significance $(* *)$.

\section{Results and Discussion}

\subsection{Cellulose crystallinity and ultra-structural characterization}

XRD and solid-state ${ }^{13} \mathrm{C}$ NMR have most widely been used techniques to evaluate the crystallinity of cellulose [34]. In the present paper, ${ }^{13} \mathrm{C}$ CP/MAS NMR spectroscopy was used to determine the crystallinity and the ultra-structural components of cellulose in transgenic and control plants (Fig. 1a, 1b and 1c). The crystallinity index (CrI) was determined by using the ratio of the peak integration of C-4 crystalline carbon region ( $\delta 85-92 \mathrm{ppm})$ to the integral of the entire C-4 region $(\delta 80-92$ ppm) $[35,36]$ and were between 55.0-58.6\% for selected transgenic lines in comparison to control (Fig. 2). Compared with the control, $P d K O R 1$ and $P d K O R 2$ plants exhibited between $\sim 3-7 \%$ of increase in cellulose crystallinity. The increase in cellulose crystallinity in transgenic samples is in agreement with the previous studies where down regulated or knock down cellulose biosynthesis variants also exhibited higher crystalline cellulose [24, 37].

\section{INSERT FIG. 1a, 1b and 1c}

\section{INSERT FIG. 2}


A two peak fit analysis showed essentially the low ordered amorphous and high ordered crystalline regions in isolated cellulose samples, where the relative quantities of these two regions determines the crystallinity of cellulose. However, as it is also known that cellulose can exist in several other crystallographic forms or allomorphs. Estimation of these amorphous regions is required to determine its supra molecular structure comprising the various crystalline and non-crystalline domains within individual RNAi transgenics of $P d K O R 1$ and $P d K O R 2$. Therefore, we used the seven line-fit analysis of ${ }^{13} \mathrm{C}$ CPMAS spectrum to measure the relative proportions of cellulose ultra-structural components, namely $I_{\alpha}, I_{\beta}, I_{\alpha+\beta}$ and para-crystalline, as well as cellulose accessible and inaccessible fibril surfaces as described by Larsson et al. [36].

Lorentzian and Gaussian lines with fixed center position and width were applied for the crystalline and amorphous region, respectively as reported previously [35, 38]. The spectral fitting for the C-4 region of the CP/MAS ${ }^{13} \mathrm{C}$ NMR spectrum of the isolated cellulose from one transgenic and control line is shown in Fig. $1 \mathrm{~b}$ and 1c, where the signal assignment shows the separate lines for crystalline cellulose $\mathrm{I}_{\alpha}, \mathrm{I}_{\beta}$, and mixed cellulose $\mathrm{I}_{\alpha+\beta}$ peak, a para-crystalline signal, as well as resonances attributed to the accessible and inaccessible fibril surfaces. Lorentzian line-shapes were used for the carbon resonances of cellulose $I_{\alpha}, I_{\alpha+\beta}, I_{\beta}$ and para-crystalline cellulose, while Gaussian lines were used for resonances corresponding to inaccessible and accessible fibril surfaces of the amorphous cellulose. The results of the fitting procedure on control Populus cellulose is compiled in Table 1.

The average lateral fibril dimension (LFD) and lateral fibril aggregate dimensions (LFAD) [39, 40] were also estimated for transgenic and control samples and the results are displayed in Table 2. The line fit analysis revealed substantial differences in the relative abundance of crystalline cellulose and micro-fibrils size in transgenic lines compared to the control plants (Fig. 3 \& Table1). In both PdKORI lines, there was a decrease in the relative amount of $\mathrm{I}_{\alpha}(\sim 10-17 \%)$ allomorph, which is accompanied by subsequent increase ( $\sim 6-13 \%)$ in cellulose $\mathrm{I}_{\beta}$ and also $\mathrm{I}_{\alpha+\beta}$ cellulose $(\sim 12 \%)$, the domain shared by both $\mathrm{I}_{\alpha}$ and $\mathrm{I}_{\beta}$ types of cellulose. In contrast, $P d K O R 2$ lines exhibited lower $\mathrm{I}_{\alpha+\beta}$ cellulose content but subsequent increase was observed in the resonances dominated by crystalline $I_{\alpha}$ and $I_{\beta}$ domain. The amount of para- 
crystalline cellulose was found to have increased in both RNAi constructs in the range of $\sim 3-10 \%$ when compared with control (Fig. 3a), with maximum increase was detected for the PdKOR2-1. A relatively higher amount of the crystalline and para-crystalline cellulose in the transgenic lines thus resulted in the overall increase of cellulose percent crystallinity within the transgenic samples, which further revealed that the KOR regulation or expression may have affected the orientation of micro-fibril deposition or may have altered the fibril diameters. The para-crystalline signal that originated in the crystalline region of 88.6-88.4 ppm is mostly assumed as a well-ordered structure and relatively considered as inaccessible to solvents [41]. Nonetheless, this region also provides a slow transition between fully amorphous and fully crystalline phases along the cellulose fibrils.

A combined CPMAS-line fit study by Sannigrahi et al. [42] showed that the relative proportions of para-crystalline and amorphous cellulose decreased after enzymatic hydrolysis of pretreated pine, indicating the preferential degradation of these forms by cellulose enzyme. Thus, the higher amount of para-crystalline cellulose in the sample is expected to exhibit enhanced enzymatic hydrolysis conversion as also described in another study by $\mathrm{Pu}$ et al. [43]. Apart from crystalline cellulose peaks in ${ }^{13} \mathrm{C}$ CPMAS, a broad amorphous peak at 84.0 ppm (Fig. 1b) essentially consists of two main overlapped peaks from solvent accessible (accessible fibril surfaces in contact with water or solvent) and solvent inaccessible cellulose fibril surfaces (fibril-fibril contact surfaces resulting from fibril distortion). The relative proportion of cellulose at accessible and inaccessible fibril surfaces is also shown in Figure $3 \mathrm{~b}$. The relative amount of accessible cellulose surface decreased noticeably in all transgenic lines when compared to control. PdKORI-1 showed $\sim 66 \%$, decrease in accessible surface and PdKOR2-1 and PdKOR2-2 lines displayed $\sim 17 \%$ and $\sim 40 \%$ decrease in accessible surface, respectively (Fig. $3 \mathrm{~b}$ ). Solvent inaccessible surfaces are the fibril-fibril contact surfaces and the surfaces created from the distortions in the fibril interior. The inaccessible surface area was observed to increase from 3-7\% in all the transgenic lines in comparison to control, which has been attributed to fibril distortions or dislocation [28]. Consistent with the crystallinity results, the transgenic lines also showed increase in the LFD (Table1), which is directly correlated with the relative amount of accessible fibril surfaces [44]. 
KOR has been proposed to have several roles in cell wall synthesis, including 1) cleavage of the steryol glycosides, the proposed precursors [45], 2) assembly of the glucan chains in cellulose microfibrils and maintenance of the degree of polymerization [27] and 3) release of stress around the cellulose fibril and maintenance of micro-fibril angle [26]. Furthermore, KOR down-regulation possibly affected the size of cellulose fibrils in the cell wall by relaxing the micro-fibril chains under tension, controlling the fibril distortions and therefore possibly increased the interior order and fibril dimensions. The increase in LFD of cellulose micro-fibrils in PdKOR transgenic lines appears to be related with the increased amount of crystalline cellulose through alterations in micro-fibril angle or via biosynthesis as also shown earlier by Taylor et al. [46]. However, in contrast, the LAFD characterizing the thicker cellulose fibrils in the cellulose crystallites were reduced in all lines. Ding and Himmel [47] have proposed a cellulose micro-fibril model where several single cellulose micro-fibrils in cellulose synthase complex (CSC) coalescence to form larger macro-fibrils bundles or aggregates which later split into smaller cellulose fibrils. Based on this model, it is likely that the transgenic lines that exhibited decreased LFAD were a direct outcome of KOR down regulation that produced comparatively lower amounts of cellulose and subsequently lower cellulose micro-fibril aggregates. In addition, the altered hemicellulose and lignin contents could also possibly affect the fibril aggregation. Nevertheless, our results indicated that the KOR transgenic studied here have a comparatively higher crystallinity and varied cellulose ultrastructure, suggesting that manipulation of a single gene in the cellulose pathway may impact on cellulose microfibril production, deposition and organization during plant secondary cell wall growth."

\section{INSERT TABLE $1 \& 2$}

\section{INSERT FIGURE 3}

\subsection{Gel permeation chromatography}

The weight average degree of polymerization $\left(\mathrm{DP}_{\mathrm{w}}\right)$ of cellulosic material determines the relative abundance of terminal and interior $\beta$-glucosidic bonds [48] and is an important rate-determining factor associated with the enzymatic hydrolysis. It has been reported earlier [49] that substrates with low $\mathrm{DP}_{\mathrm{w}}$ values have readily accessible glucan chain for the enzyme degradation during the hydrolysis. Therefore, 
it is important to understand the change in the molecular weight and $\mathrm{DP}_{\mathrm{w}}$ of cellulose in genetically modified plants. In the present study, all the transgenic lines exhibited lower degree of polymerization in comparison with control (Fig. 4a). For the PdKOR1-2 exhibited a $\sim 47 \%$ reduction in $\mathrm{DP}_{\mathrm{w}}(\mathrm{P}=0.04)$, followed by line PdKOR2-1 ( 30\%). The transgenic PdKOR1-1 also showed a decrease in $\mathrm{DP}_{\mathrm{w}}, \sim 12 \%$. These observations are consistent with the previous studies that have proposed an editing role for KOR involving cleaving and removing defective micro-fibrils from well-developed cellulose chain. According to Molhoj et al. [50], in such modified cellulose pathways, some genes may act as a cellulase that hydrolyzes longer polysaccharides such as $\beta, 1-4$-linked glucan chain and produces non-crystalline cellulose. Interestingly, Maloney [14], in another study, indicated that an altered modified cellulose pathway did not affect the molecular weight distribution of cellulose in Populus. The variation in our molecular weight results, however, clearly demonstrated that the alteration in cellulose pathways by specific genetic modification has resulted in lower DP values in transgenic plants in comparison to the control.

We also characterized hemicellulose molecular weights in order to understand the effect of cellulose biosynthesis on the growth of hemicellulose chain scissions. There was no major change in the $\mathrm{DP}_{\mathrm{w}}$ of hemicellulose for either PdKOR1 or PdKOR2 transgenic, which implies that cellulose biosynthesis may have little effect on the hemicellulose properties.

\section{INSERT FIGURE 4}

\subsection{Lignin Structural Characterization}

In order to understand the impact of genetic manipulation of cellulose biosynthesis on lignin structure, the control and transgenic Populus lines were subjected to partial removal of polysaccharides by repeated cellulysin-cellulase treatment and the ${ }^{13} \mathrm{C}-{ }^{1} \mathrm{H}$ HSQC NMR spectra (Fig 5) were obtained on the resultant lignin-rich Populus samples. The majority of the observed lignin side-chain units were $\beta$ ether (A); however, traces of phenylcoumaran (B) and resinol (C) were also detected as indicated by the presence of $\alpha$ and $\beta$ cross signals at $\delta \mathrm{C} / \delta \mathrm{H} 71.5 / 4.80\left(\mathrm{~A}_{\alpha}\right), 86.0 / 4.1\left(\mathrm{~A}_{\beta}\right), 87.5 / 5.5\left(\mathrm{~B}_{\alpha}\right), 54.0 / 3.5\left(\mathrm{~B}_{\beta}\right)$ and 83.4/4.6 $\left(\mathrm{C}_{\alpha}\right)$ and 53.0/3.1 $\left(\mathrm{C}_{\beta}\right) \mathrm{ppm}[51,52]$ (Fig. 5). The relative amount of the side chain sub-units were 
estimated from the volume integration of $\mathrm{A}_{\alpha}, \mathrm{B}_{\alpha}$ and $\mathrm{C}_{\alpha}$ cross peaks and was determined to be 80:3:17 A:B:C, respectively. The major correlations at $\delta \mathrm{C} / \delta \mathrm{H} 55.0 / 3.8$ and $20.5 / 1.9 \mathrm{ppm}$ confirm the presence of methoxyl and acetyl groups, respectively. The lignin aromatic units syringyl (S) and guaiacyl (G) units were identified based on the correlations at $\delta \mathrm{C} / \delta \mathrm{H} 103.3 / 6.8\left(\mathrm{~S}_{2,6}\right), 111.4 / 7.0\left(\mathrm{G}_{2}\right), 115 / 6.7\left(\mathrm{G}_{5}\right)$ and 119.5/6.9 $\left(\mathrm{G}_{6}\right)$ ppm (Fig. 5). The HSQC analysis demonstrated that control Populus lignin is syringyl rich with $\beta$-ether, phenylcoumaran and resinol side chain units. For the various transgenic lines, the relative amount of lignin side-chain and aromatic units did not vary significantly from those values described above for the control plants. Surprisingly, the $p$-hydroxy benzoyl units, typically observed in Populus were not detected in the control and transgenic samples. Further, the relative abundances as measured by integrating the anomeric carbon contours area of the side chains and the S/G ratio of one characteristic poplar sample are listed in Table SI3. Thus, modifications in the cellulose biosynthesis pathway has observed no significant effects on the lignin structure.

\section{Conclusions}

The results presented here provide insight into the key molecular features of biomass recalcitrance specifically those associated with cellulose and hemicellulose ultra-structure that are modified as a result of modified expression of a single candidate cellulose biosynthesis pathway gene. The ultra-structural analyses showed that the cellulose pathway Populus variants had altered cell wall characteristics specifically related to the cellulose biopolymer. The transgenic lines demonstrated important variations in cellulose crystallinity, allomorph distribution, and cellulose degree of polymerization compared to the empty vector control plants. Additionally, the properties of cellulose allomorph abundance and accessibility were found to be variable. Further application of the cellulose characterization techniques beyond the traditional measurement of cellulose abundance to comprehensive studies of cellulose properties in larger transgenic and naturally variable populations is expected to provide deeper insights. Studying cell wall structure and genetically modified traits may help to understand the complex nature of lignocellulosic material and better predict the sugar release efficiency of such samples. Such insights will contribute to the design and development of precisely tailored plants for enhanced biofuels production. 


\section{Acknowledgements}

This manuscript has been authored by UT-Battelle, LLC under contract no. DE-AC05-00OR22725 with the U.S. Department of Energy. The BioEnergy Science Center is supported by the Office of Biological and Environmental Research in the U.S. Department of Energy. Mass spectrometry analysis was carried out by the U.S. Department of Energy Office of Biological and Environmental Research supported Bioenergy Research Center proteomics pipeline. The publisher, by accepting the article for publication, acknowledges that the United States Government retains a non-exclusive, paid-up, irrevocable, worldwide license to publish or reproduce the published form of this manuscript, or allow others to do so, for United States Government purposes. The Department of Energy will provide public access to these results of federally sponsored research in accordance with the DOE Public Access Plan (http://energy.gov/downloads/doe-public-access-plan).

\section{References}

[1] Yuan JS, Tiller KH, Al-Ahmad H, Stewart NR, Stewart CN, Jr. Plants to power: bioenergy to fuel the future. Trends Plant Sci 2008;13:421.

[2] Hill J, Nelson E, Tilman D, Polasky S, Tiffany D. Environmental, economic, and energetic costs and benefits of biodiesel and ethanol biofuels. PNAS 2006;103:11206.

[3] Gray KA, Zhao L, Emptage M. Bioethanol. Curr Opin Chem Biol 2006;10:141.

[4] Ragauskas AJ, Williams CK, Davison BH, Britovsek G, Cairney J, Eckert CA, et al. The Path Forward for Biofuels and Biomaterials. Science 2006;311:484.

[5] Feldman D. Wood — chemistry, ultrastructure, reactions, by D. Fengel and G. Wegener, Walter de Gruyter, Berlin and New York, 1984, 613 pp. Price: 245 DM. J Polym Sci: Polym Lett Ed.1985;23:601.

[6] Hall M, Bansal P, Lee JH, Realff MJ, Bommarius AS. Cellulose crystallinity--a key predictor of the enzymatic hydrolysis rate. The FEBS J 2010;277:1571. 
[7] Chauve M, Barre L, Tapin-Lingua S, Silva Perez Dd, Decottignies D, Perez S, et al. Evolution and impact of cellulose architecture during enzymatic hydrolysis by fungal cellulases. Adv Biosci Biotechnol 2013;04:1095.

[8] Rubin EM. Genomics of cellulosic biofuels. Nature 2008;454:841.

[9] Pan X, Kadla JF, Ehara K, Gilkes N, Saddler JN. Organosolv ethanol lignin from hybrid poplar as a radical scavenger: relationship between lignin structure, extraction conditions, and antioxidant activity. J Agric Food Chem 2006;54:5806.

[10] Wyman CE, Dale BE, Elander RT, Holtzapple M, Ladisch MR, Lee YY. Coordinated development of leading biomass pretreatment technologies. Bioresour Technol 2005;96:1959.

[11] Kumar R, Mago G, Balan V, Wyman CE. Physical and chemical characterizations of corn stover and poplar solids resulting from leading pretreatment technologies. Bioresource Technol 2009;100:3948.

[12] Gressel J. Transgenics are imperative for biofuel crops. Plant Sci 2008;174:246.

[13] Fu C, Mielenz JR, Xiao X, Ge Y, Hamilton CY, Rodriguez M, et al. Genetic manipulation of lignin reduces recalcitrance and improves ethanol production from switchgrass. PNAS 2011;108:3803.

[14] Maloney VJ, Samuels AL, Mansfield SD. The endo-1,4- $\beta$-glucanase Korrigan exhibits functional conservation between gymnosperms and angiosperms and is required for proper cell wall formation in gymnosperms. New Phytologist 2012;193:1076.

[15] Vailhé MAB, Migné C, Cornu A, Maillot MP, Grenet E, Besle JM, et al. Effect of Modification of theO-Methyltransferase Activity on Cell Wall Composition, Ultrastructure and Degradability of Transgenic Tobacco. J Sci Food Agric 1996;72:385.

[16] Guo D, Chen F, Inoue K, Blount JW, Dixon RA. Downregulation of Caffeic Acid 3-OMethyltransferase and Caffeoyl CoA 3-O-Methyltransferase in Transgenic Alfalfa: Impacts on Lignin Structure and Implications for the Biosynthesis of G and S Lignin. The Plant Cell Online 2001;13:73.

[17] Dinus RJ. Genetic Modification of short rotation Poplar biomass feedstock for efficient conversion to ethanol. Environmental Sciences Division, ORNL; 2000. 
[18] Foston M, Hubbell CA, Samuel R, Jung S, Fan H, Ding S-Y, et al. Chemical, ultrastructural and supramolecular analysis of tension wood in Populus tremula $\mathrm{x}$ alba as a model substrate for reduced recalcitrance. Energy Environ Sci 2011;4:4962.

[19] Somerville C. Cellulose Synthesis in Higher Plants. Annu Rev Cell Dev Biol 2006;22:53.

[20] Sato S, Kato T, Kakegawa K, Ishii T, Liu Y-G, Awano T, et al. Role of the Putative MembraneBound Endo-1,4- $\beta$-Glucanase KORRIGAN in Cell Elongation and Cellulose Synthesis in Arabidopsis thaliana. Plant Cell Physiol 2001;42:251.

[21] Sturm A, Tang G-Q. The sucrose-cleaving enzymes of plants are crucial for development, growth and carbon partitioning. Trends Plant Sci.1999;4:401.

[22] Delmer DP. Cellulose biosynthesis: Exciting times for a difficult field of study. Ann Rev Plant Physiol Plant Mol Bio 1999;50:245.

[23] Peng L, Kawagoe Y, Hogan P, Delmer D. Sitosterol- $\beta$-glucoside as Primer for Cellulose Synthesis in Plants. Science 2002;295:147.

[24] Szyjanowicz PM, McKinnon I, Taylor NG, Gardiner J, Jarvis MC, Turner SR. The irregular xylem 2 mutant is an allele of korrigan that affects the secondary cell wall of Arabidopsis thaliana. The Plant J: Cell Mol Bio 2004;37:730.

[25] Maloney VJ, Mansfield SD. Characterization and varied expression of a membrane-bound endobeta-1,4-glucanase in hybrid poplar. Plant Biotechnol J 2010;8:294.

[26] Molhoj M, Pagant S, Hofte H. Towards understanding the role of membrane-bound endo-beta1,4-glucanases in cellulose biosynthesis. Plant Cell Physiol 2002;43:1399.

[27] Foston M, Ragauskas AJ. Changes in lignocellulosic supramolecular and ultrastructure during dilute acid pretreatment of Populus and switchgrass. Biomass Bioenergy 2010;34:1885.

[28] Payyavula SR, Bali G, Jawdy SS, Yee LK, Bryan CA, Engle N, et al. KORRIGAN-like genes are important in cellulose biosynthesis and carbon allocation and partitioning in Populus plants. J Exp Botany 2014; In Review. 
[29] Kumar R, Hu F, Hubbell CA, Ragauskas AJ, Wyman CE. Comparison of laboratory delignification methods, their selectivity, and impacts on physiochemical characteristics of cellulosic biomass. Bioresour Technol 2013;130:372.

[30] Wood BF, Conner AH, Hill CG. The effect of precipitation on the molecular weight distribution of cellulose tricarbanilate. J Appl Polym Sci 1986;32:3703.

[31] Xue BL, Wen JL, Xu F, Sun RC. Structural characterization of hemicelluloses fractionated by graded ethanol precipitation from Pinus yunnanensis. Carbohydr Res 2012;352:159.

[32] Zhang A, Lu F, Sun R-C, Ralph J. Isolation of Cellulolytic Enzyme Lignin from Wood Preswollen/Dissolved in Dimethyl Sulfoxide/N-Methylimidazole. J Agric Food Chem 2010;58:3446.

[33] Berlin A, Balakshin M, Gilkes N, Kadla J, Maximenko V, Kubo S, et al. Inhibition of cellulase, xylanase and $\beta$-glucosidase activities by softwood lignin preparations. J Biotechnol 2006;125:198.

[34] Park S, Baker John O, Himmel ME, Parilla PA, Johnson DK. Cellulose crystallinity index: measurement techniques and their impact on interpreting cellulase performance. Biotechnology for Biofuels 2010; 3:10.

[35] Wickholm K, Larsson PT, Iversen T. Assignment of non-crystalline forms in cellulose I by CP/MAS 13C NMR spectroscopy. Carbohydr Res 1998;312:123.

[36] Larsson PT, Wickholm K, Iversen T. A CP/MAS13C NMR investigation of molecular ordering in celluloses. Carbohydr Res 1997;302:19.

[37] Takahashi J, Rudsander UJ, Hedenström M, Banasiak A, Harholt J, Amelot N, et al. KORRIGAN1 and its Aspen Homolog PttCe19A1 Decrease Cellulose Crystallinity in Arabidopsis Stems. Plant Cell Physiol 2009;50:1099.

[38] Lennholm H, Larsson T, Iversen T. Determination of cellulose I $\alpha$ and I $\beta$ in lignocellulosic materials. Carbohydr Res 1994;261:119.

[39] Newman RH. Evidence of assignment of 13C NMR signals to cellulose crystallite surfaces in wood, pulp and isolated cellulose. Holzforschung - International Journal of the Biology, Chemistry, Physics and Technology of Wood; 1998, p. 157. 
[40] Heux L, Dinand E, Vignon MR. Structural aspects in ultrathin cellulose microfibrils followed by 13C CP-MAS NMR. Carbohydr Polym 1999;40:115.

[41] Zuckerstätter G, Schild G, Wollboldt P, Röder T, Weber KH, Sixta H. The elucidation of cellulose supramolecular structure by 13C CPMAS NMR Lenzinger Berichte 2009;87:38.

[42] Sannigrahi P, Miller SJ, Ragauskas AJ. Effects of organosolv pretreatment and enzymatic hydrolysis on cellulose structure and crystallinity in Loblolly pine. Carbohydr Res 2010;345:965.

[43] Pu Y, Ziemer C, Ragauskas AJ. CP/MAS 13C NMR analysis of cellulase treated bleached softwood kraft pulp. Carbohydr Res 2006;341:591.

[44] Newman RH. Estimation of the lateral dimensions of cellulose crystallites using 13C NMR signal strengths. Solid State Nucl Magn Reson 1999;15:21.

[45] Peng L, Kawagoe Y, Hogan P, Delmer D. Sitosterol-beta-glucoside as primer for cellulose synthesis in plants. Science 2002;295:147.

[46] Taylor NG. Cellulose biosynthesis and deposition in higher plants. New Phytologist 2008;178:239.

[47] Ding S-Y, Himmel ME. The Maize Primary Cell Wall Microfibril: A New Model Derived from Direct Visualization. J Agric Food Chem 2006;54:597.

[48] Zhang Y-HP, Lynd LR. Toward an aggregated understanding of enzymatic hydrolysis of cellulose: Noncomplexed cellulase systems. Biotechnol Bioeng 2004;88:797.

[49] Wood TM. Properties and mode of action of cellulases. Biotechnol Bioeng Symposium 1975:111.

[50] Mølhøj M, Pagant S, Höfte H. Towards Understanding the Role of Membrane-bound Endo- $\beta-1,4-$ glucanases in Cellulose Biosynthesis. Plant Cell Physiol 2002;43:1399.

[51] Samuel R, Foston M, Jaing N, Cao S, Allison L, Studer M, et al. HSQC (heteronuclear single quantum coherence) $13 \mathrm{C}-1 \mathrm{H}$ correlation spectra of whole biomass in perdeuterated pyridinium chlorideDMSO system: An effective tool for evaluating pretreatment. Fuel 2011;90:2836.

[52] Pu Y, Chen F, Ziebell A, Davison B, Ragauskas A. NMR Characterization of C3H and HCT Down-Regulated Alfalfa Lignin. Bioenerg Res 2009;2:198. 


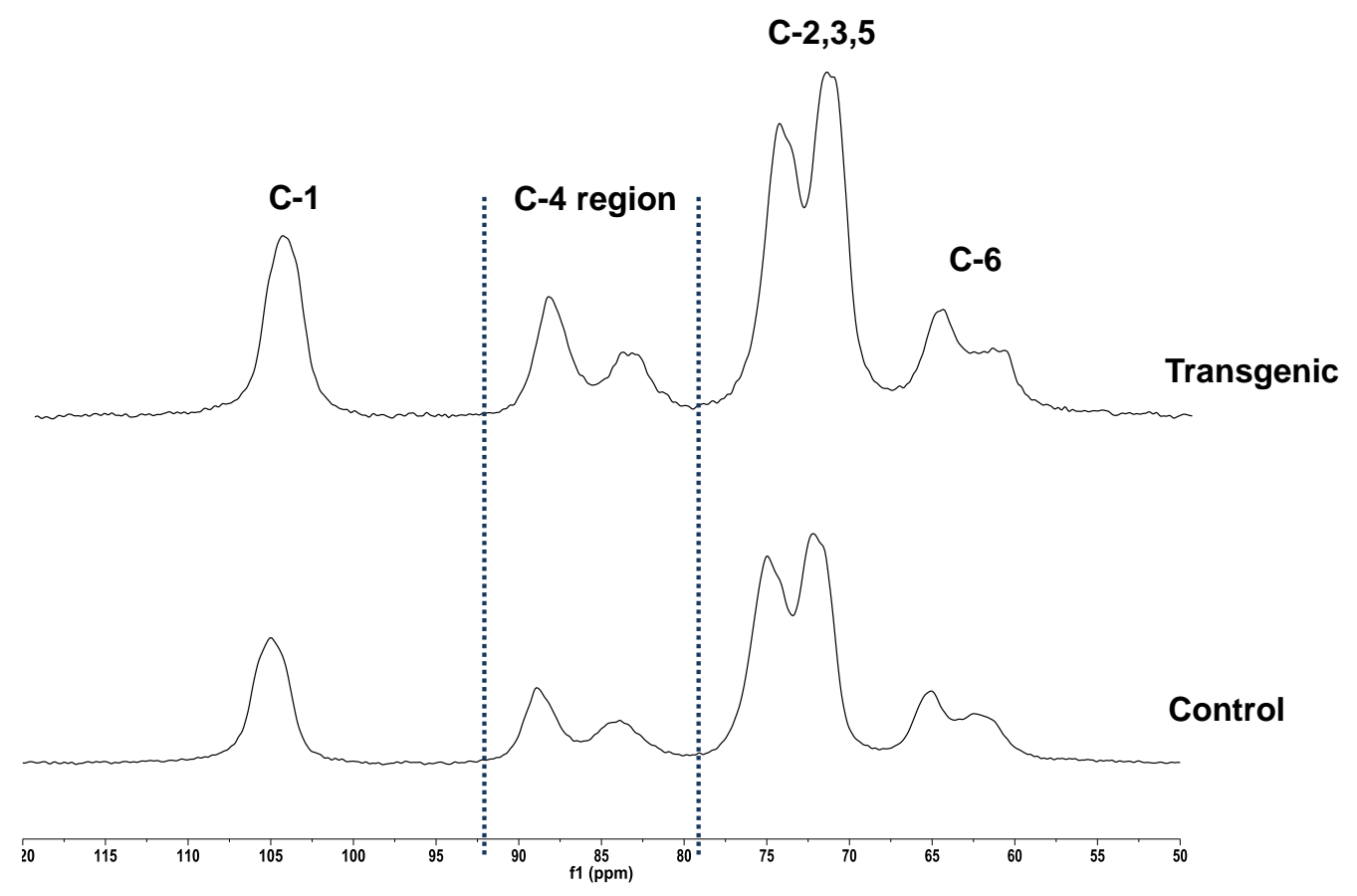

Fig. 1a. 

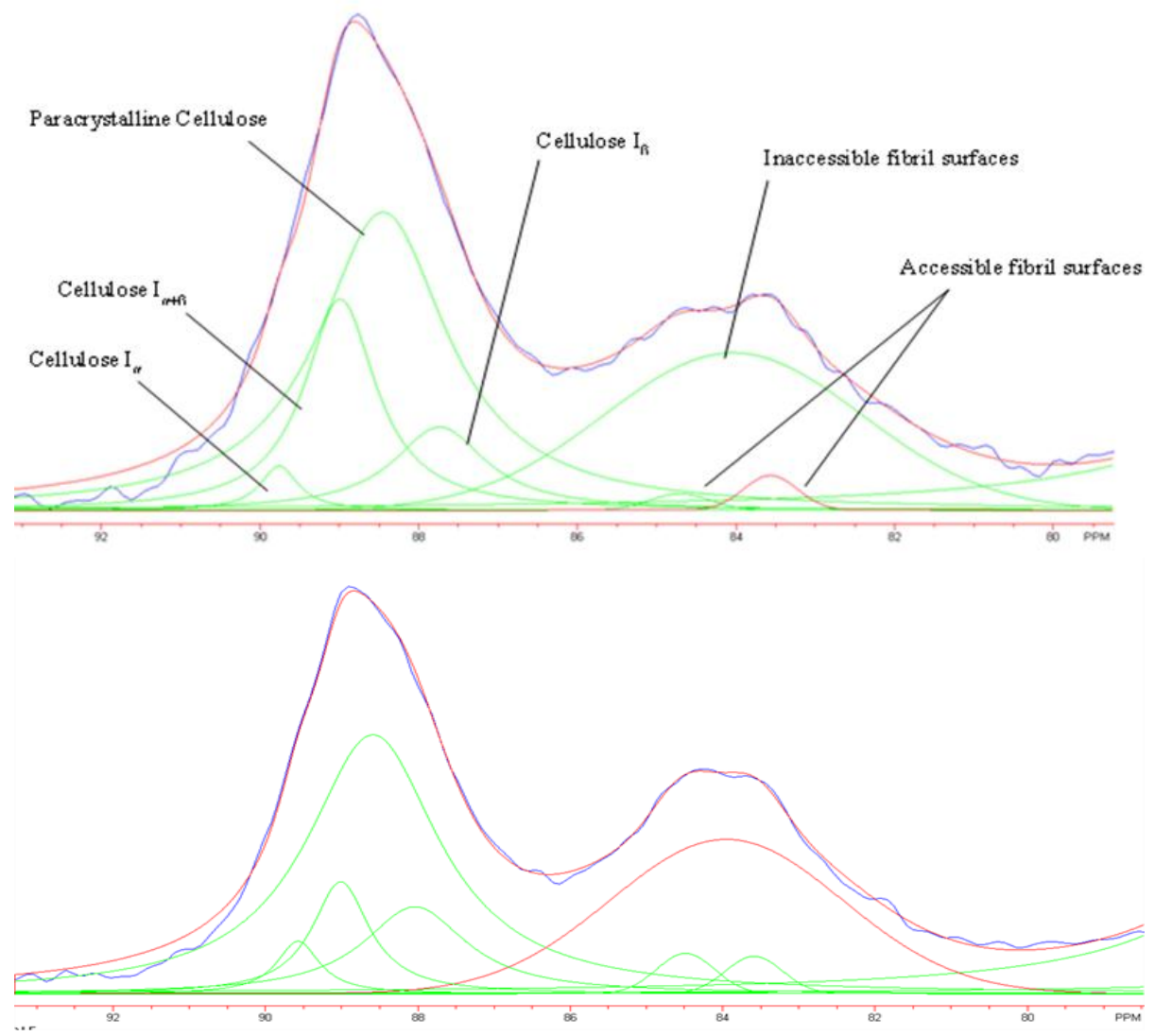

Fig. 1b (top) and Fig. 1c(bottom) 


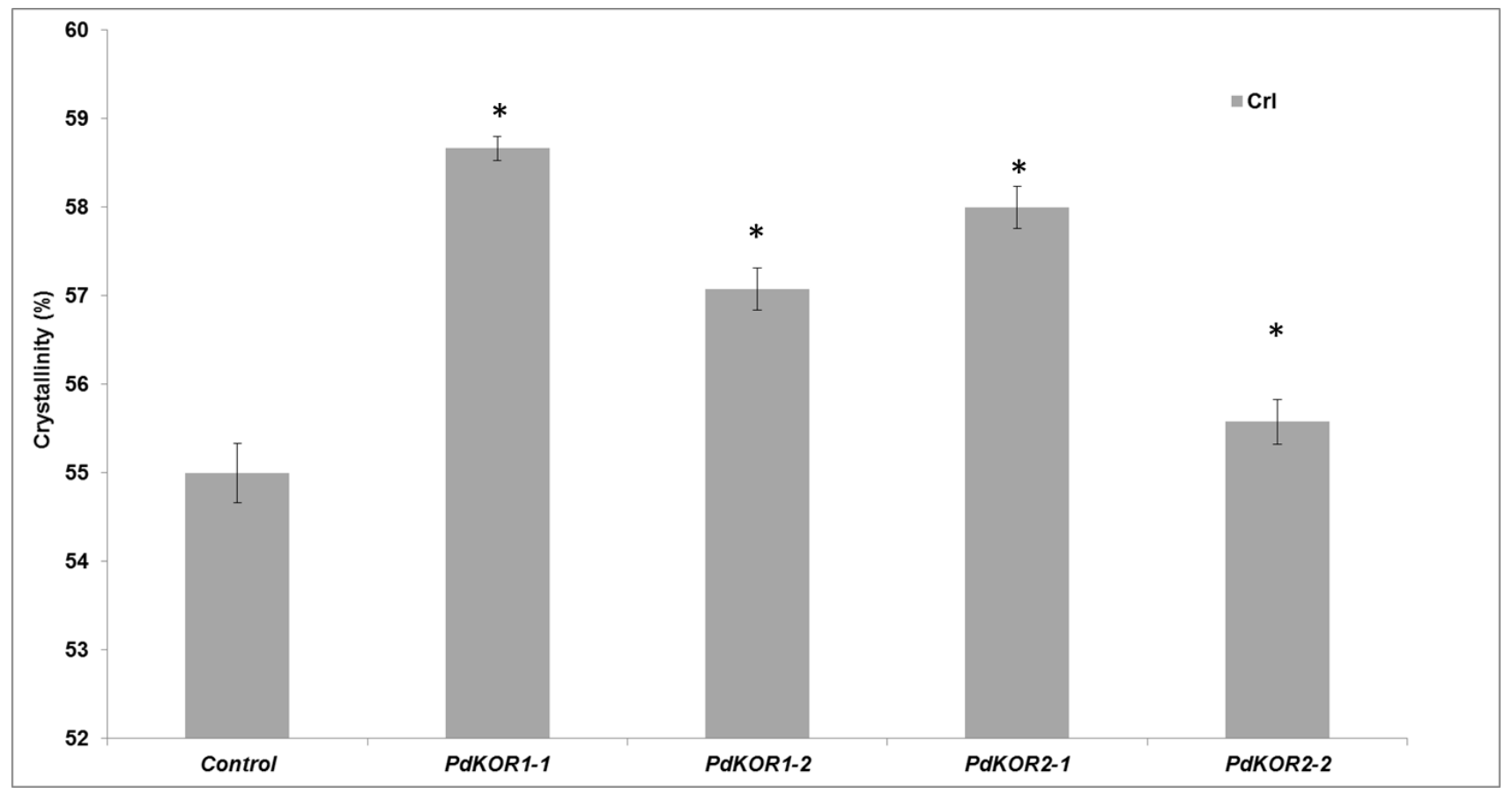

Fig. 2. 


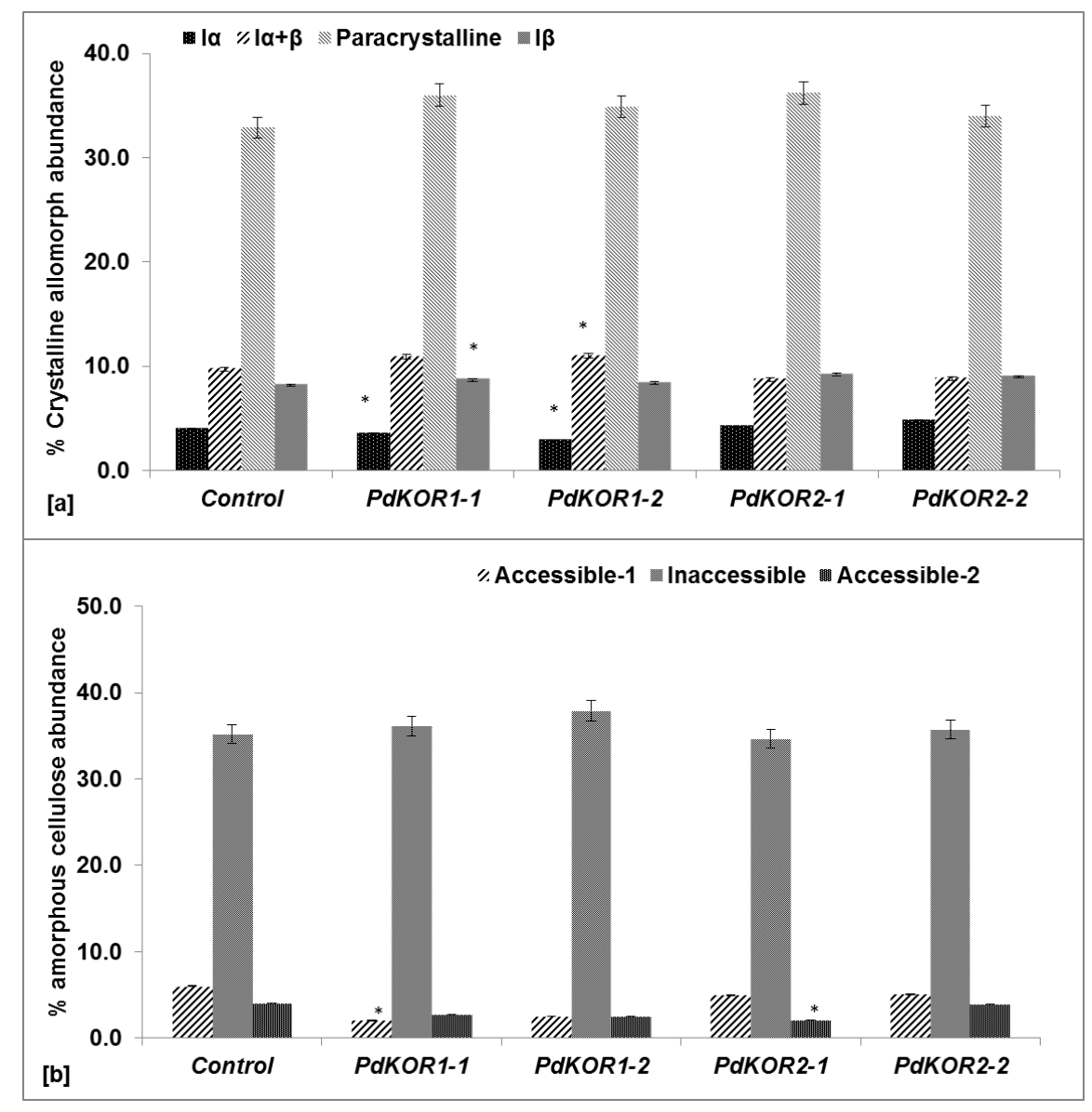

Fig.3. 

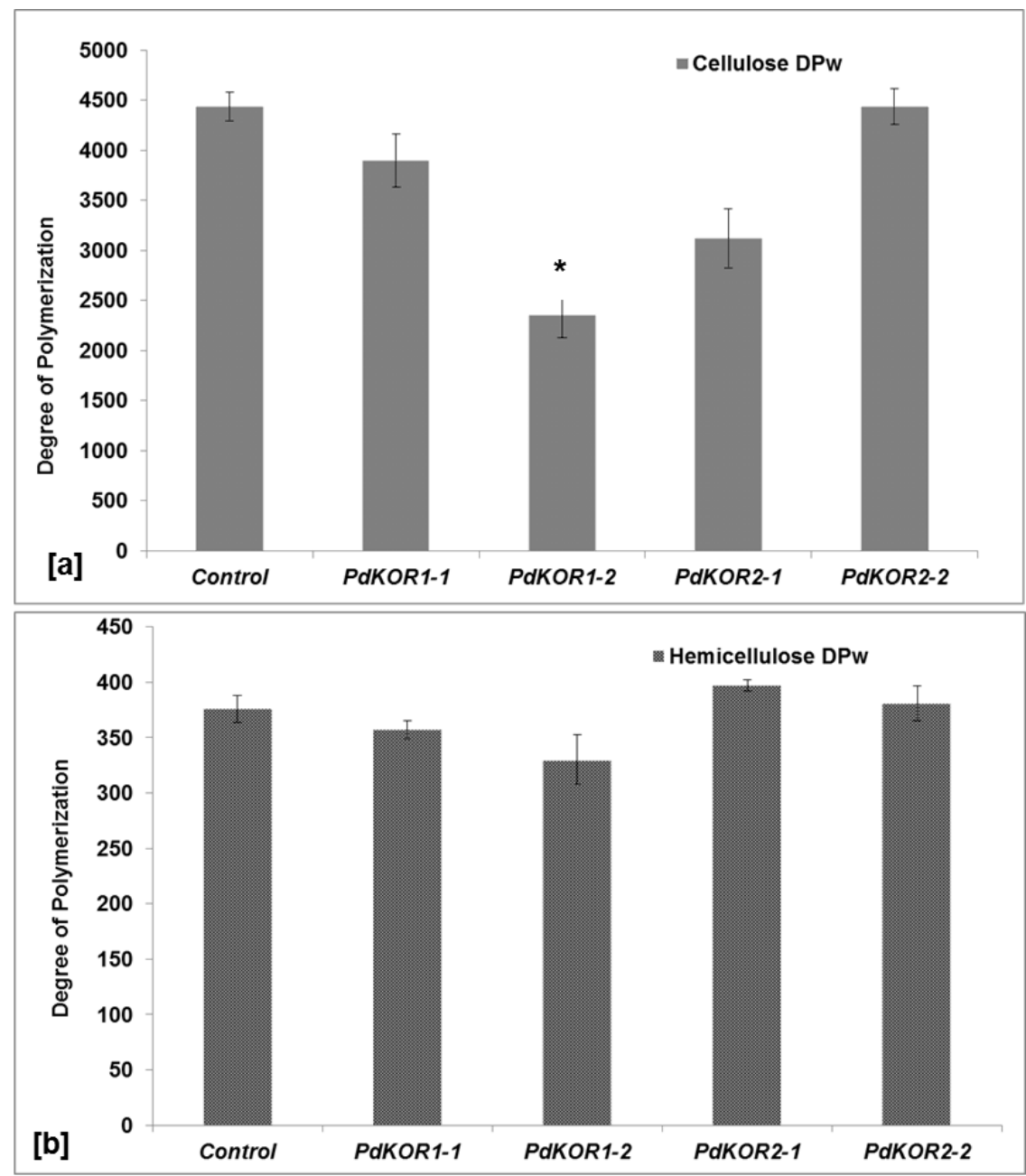

Fig.4a and Fig. 4b 


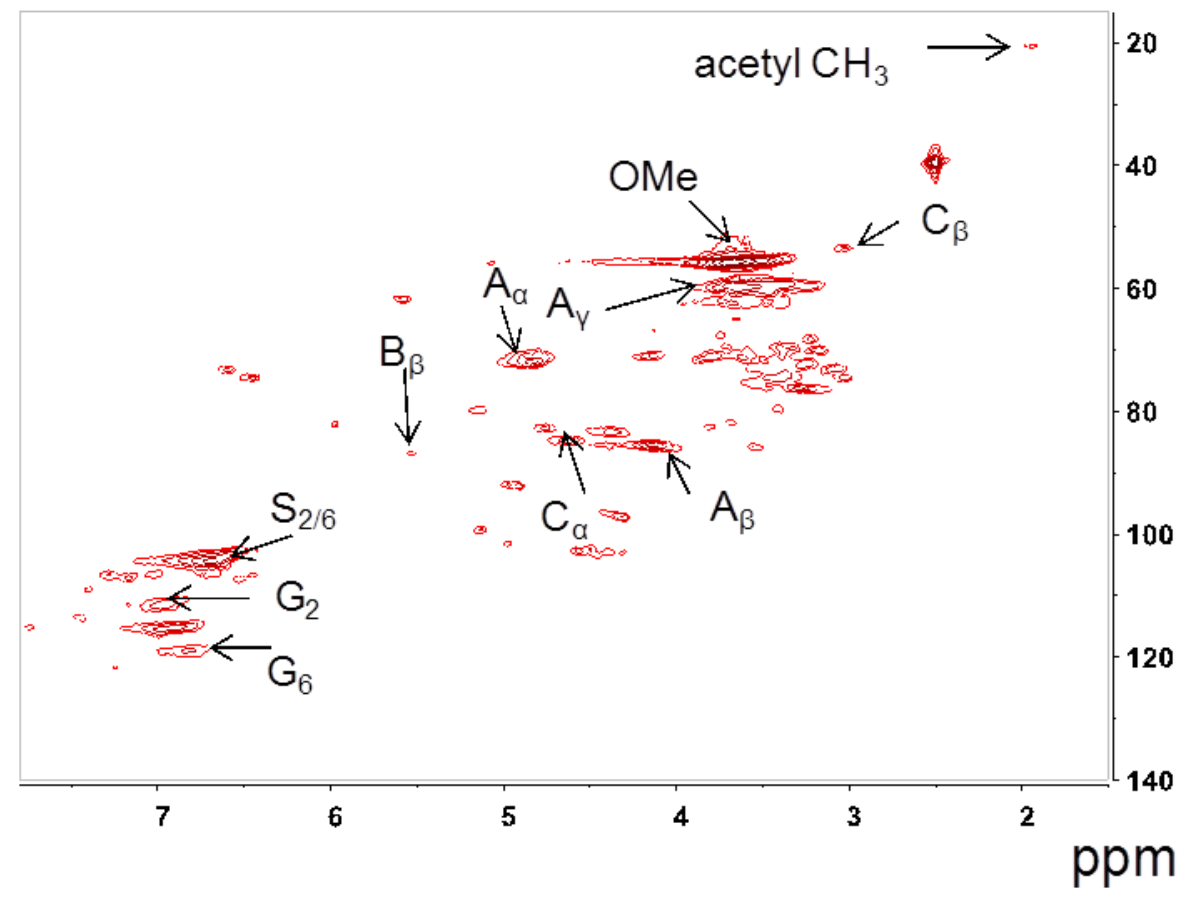

Fig. 5a

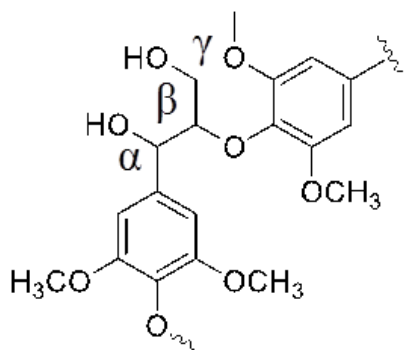

A

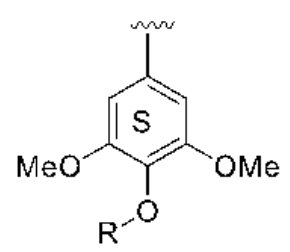

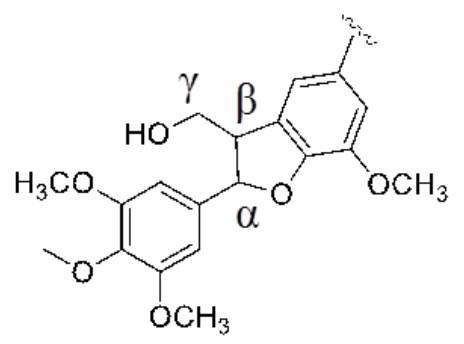

B

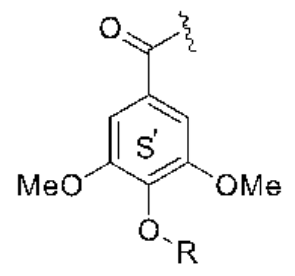

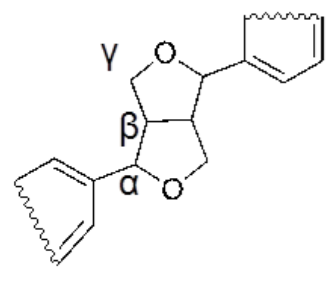

C<smiles>[R]Oc1ccc(C#N)cc1OC</smiles>

Fig. 5b 


\section{Figure Captions}

Fig. 1a. ${ }^{13}$ C-CPMAS spectra of transgenic (top) and control (bottom) lines of Populus.

Fig. 1b(Top). Spectral fitting for the C-4 region of the ${ }^{13} \mathrm{C} C P / M A S$ spectrum of cellulose isolated from transgenic Populus. Blue: Line shape of C-4 region in CP/MAS ${ }^{13} \mathrm{CNMR}$ spectrum of cellulose sample before line fitting; Red: Line shape of the C-4 region of the CP/MAS ${ }^{13} \mathrm{CNMR}$ spectrum of cellulose after line fitting, whose parameters of relative intensity and line width were applied to the carbon signals attributed to cellulose $I_{\alpha}, I_{\beta}, I_{\alpha+\beta}$, paracrystalline cellulose, inaccessible, and accessible fibril surfaces (Samuel et al. 2010); Green: The carbon signals attributed to domains of cellulose $I_{\alpha}, I_{\beta}, I_{\alpha+\beta}$, paracrystalline cellulose, inaccessible, and accessible fibril surfaces.

Fig.1c(bottom). Spectral fitting for the C-4 region of the ${ }^{13} \mathrm{C} \mathrm{CP} / \mathrm{MAS}$ spectrum of cellulose isolated from control Populus.

Fig. 2. Cellulose crystallinity of selected lines, as measured by ${ }^{13} \mathrm{C}-\mathrm{CP} / \mathrm{MAS}$, Average \pm standard error, $\mathrm{n}=3$ (Transgenic) or $\mathrm{n}=5$ (control). $* \mathrm{P} \leq 0.05$

Fig. 3. Relative cellulose allomorphs abundance in control and transgenic Populus lines; a. crystalline allomorphs, b. amorphous region. The errors associated with paracrystalline, $I_{\alpha}, I_{\beta}, I_{\alpha+\beta}$ and the amorphous domains in the line fitting were found to be $\pm 3.0, \pm 1.5, \pm 1.3, \pm 2.0$ and $\pm 3.1 \%$, respectively.

Fig. 4. a. Weight average degree of polymerization $\left(\mathrm{DP}_{\mathrm{w}}\right)$ of cellulose $\mathbf{b}$. hemicellulose isolated from transgenic and control plants in Populus.

Fig. 5a. Representative ${ }^{13} \mathrm{C}-{ }^{1} \mathrm{H} 2 \mathrm{D}$ HSQC spectra of enzyme treated control Populus in perdeuterated pyridinium chloride-DMSO $\mathrm{d}_{6}$ system

Fig. 5b. Identified Populus lignin sub-units 


\section{Characterization of cellulose structure of Populus plants modified in candidate cellulose}

\section{biosynthesis genes}

Garima Bali $^{\mathrm{a}, \mathrm{b}}$, Ratayakorn Khunsupat ${ }^{\mathrm{a}}$, Hannah Akinosho ${ }^{\mathrm{a}, \mathrm{b}}$, Raja S Payyavula ${ }^{\mathrm{b}}$, Reichel Samuel ${ }^{\mathrm{a}}$, Gerald A. Tuskan ${ }^{\mathrm{b}}$, Udaya C. Kallurib ${ }^{\S}$, and Arthur J. Ragauskas ${ }^{\mathrm{a}, \mathrm{b}^{*}}$

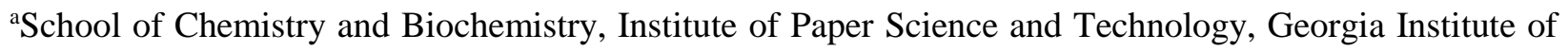
Technology, 500 10th St., Atlanta, GA, 30332, bioEnergy Science Center, Oak Ridge National Laboratory, Oak Ridge, TN, 37831

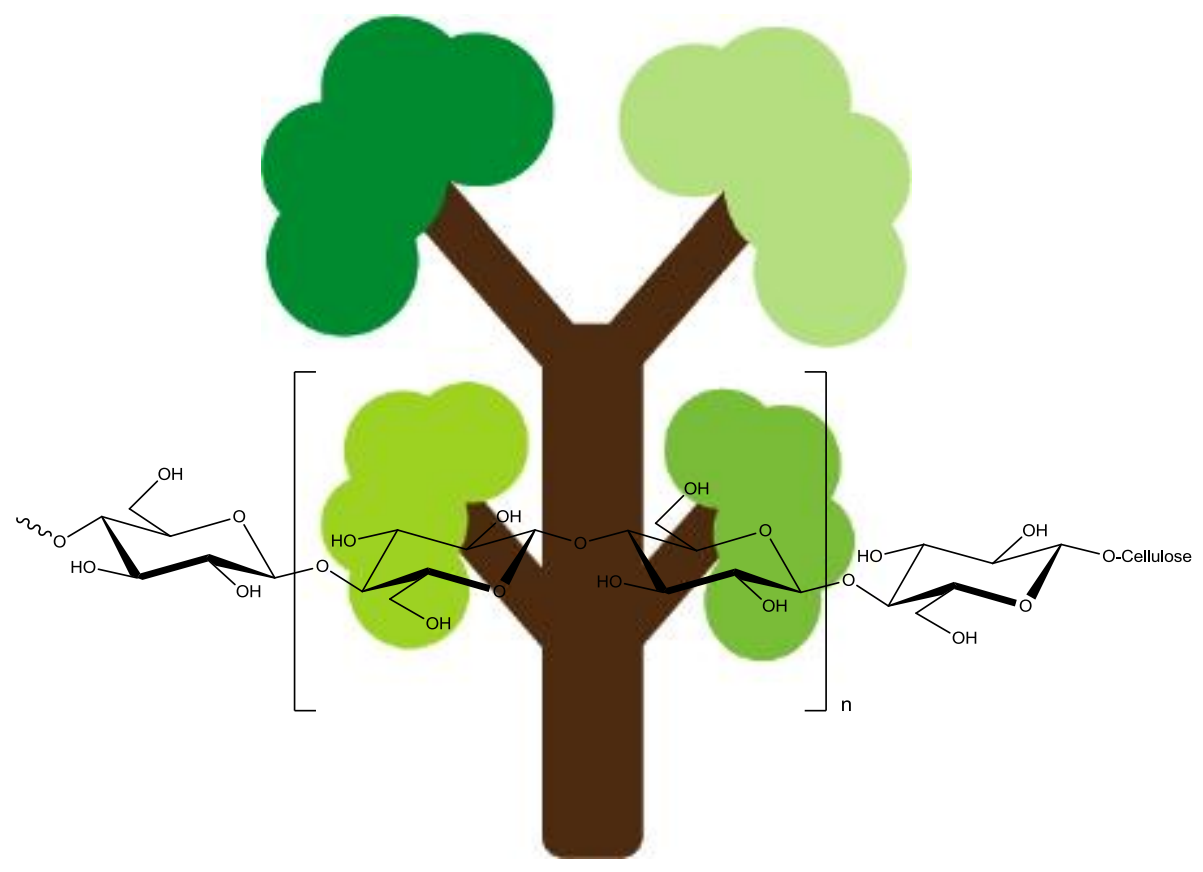


Table1: Nonlinear spectral fitting results of C-4 region for ${ }^{13} \mathrm{C}$ CPMAS spectra of isolated cellulose from control poplar. The values in parentheses are the standard deviation of 5 replicate

\begin{tabular}{|c|c|c|c|}
\hline Assignment & $\begin{array}{l}\text { Chemical shift } \\
\text { (ppm) }\end{array}$ & $\begin{array}{l}\text { Relative Intensity } \\
(\%)\end{array}$ & $\begin{array}{l}\text { Full width at half } \\
\text { maximum }(\mathrm{Hz})\end{array}$ \\
\hline $\mathrm{I}_{\alpha}$ & 89.7 & $4.01(2.5)$ & $76(7.2)$ \\
\hline $\mathrm{I}_{\beta}$ & 88.1 & $9.70(3.0)$ & $126(11.1)$ \\
\hline $\mathrm{I}_{\alpha+\beta}$ & 88.9 & $11.37(2.2)$ & $85(20.0)$ \\
\hline $\begin{array}{l}\text { Para-crystalline } \\
\text { cellulose }\end{array}$ & 88.6 & $28.69(4.2)$ & $201(35.2)$ \\
\hline $\begin{array}{l}\text { Accessible fibril } \\
\text { surfaces I }\end{array}$ & 84.4 & $2.01(0.9)$ & $103(15.0)$ \\
\hline $\begin{array}{l}\text { Accessible fibril } \\
\text { surfaces II }\end{array}$ & 83.6 & $1.65(0.8)$ & $315(42.0)$ \\
\hline Inaccessible & 83.9 & $42.56(3.6)$ & 88 (12.9) \\
\hline
\end{tabular}


Table 2. Lateral fibril dimension and lateral aggregate fibril dimension for transgenic and control Populus samples. An error analysis was conducted by performing three experimental trials. Errors associated with line fit procedure as reported previously (Foston and Ragauskas, 2010). Literature values for LFD=4-5 nm, LFAD=15-40 nm (Foston and Ragaukas, 2010).

\begin{tabular}{|l|l|l|}
\hline Line & LFD $(\mathrm{nm}) \pm 0.2$ & LFAD $(\mathrm{nm}) \pm 1.5$ \\
\hline Control & 4.4 & 38.9 \\
\hline PdKOR1-1 & 4.7 & 37.0 \\
\hline PdKOR1-2 & 4.7 & 38.5 \\
\hline PdKOR2-1 & 4.7 & 34.5 \\
\hline PdKOR2-2 & 4.5 & 36.7 \\
\hline
\end{tabular}

